\title{
Myocardial Ischemia during Combined Chemotherapy with Etoposide and Cisplatin for Non-Small Cell Lung Cancer \\ Daliborka Bursac*
}

Faculty of Medicine Novi Sad, Institute for Pulmonary Diseases of Vojvodina, Sremska Kamenica, Serbia

\begin{abstract}
Cardiovascular ischemia has been recognized as a serious but uncommon complication of chemotherapy. We report a case of myocardial ischemia during combined chemotherapy with cisplatin and etoposide for non-small cell lung cancer. A 58-year-old man with non-small cell lung cancer and previous history of coronary artery disease suffered chest pain with ECG changes during the third course of chemotherapy with cisplatin and etoposide. Chemotherapy should be used cautiously in patients with coronary risk factors.
\end{abstract}

Keywords: Myocardial ischemia; Cisplatin; Etoposide; Non-smallcell lung cancer

\section{Introduction}

Cisplatin, a platinum-based chemotherapy drug, is the cornerstone agent in the treatment of a variety of malignancies, such as carcinomas of the ovary, lung, lymphomas, sarcomas, and germ cell tumors [1]. One of the most important complications of cisplatin-based chemotherapy is the high risk of thromboembolic events, namely cardiovascular complications. In most of the cases, heart (myocardial infarction), brain (ischemic stroke), and lower limb arteries are involved [1].

\section{Case Report}

A 58-year-old man was diagnosed with right lung squamous cell carcinoma, stage IIIb (T2aN3M0,) in October 2011. He had smoked 20 cigarettes a day for 20 years and had been an ex-smoker for seven years. Past medical history included hypertension and myocardial infarction 7 years ago, for which he had undergone a triple vessel coronary artery bypass surgery. Since then the patient had remained well with no cardiac symptoms. A pre-chemotherapy ECG showed only minor non-specific ST-T wave changes (Figure 1).

The patient was treated with endoluminal brachytherapy and chemotherapy which consisted of cisplatin and etoposide. The endoluminal brachytherapy was performed in November 2011 with a total dose of $14 \mathrm{~Gy}$ in 2 fractions. The chemotherapy was started on $22^{\text {nd }}$ February 2012., with cisplatin $\left(60 \mathrm{mg} / \mathrm{m}^{2}\right.$, day 1.$)$ and etoposide $(100$ $\mathrm{mg} / \mathrm{m}^{2}$, day $1 .-3$.), in a four-week schedule. The first two cycles were administered without complications.

On day 2 of the third cycle of chemotherapy, the patient presented with precordial burning pain. Physical examination on admission was normal, blood pressure was $120 / 70 \mathrm{mmHg}$ and his heart rate was 86 beats per minute.

Initial electrocardiogram (ECG), obtained during chest pain, showed ST elevation in lead aVR, diffuse significant ST depression in precordial leads (Figure 2). Echocardiography showed inferolateral wall hypokinesia with mild impairment systolic function and ejection fraction of 50 per cent.

Serial troponin and pro-BNP (B-type natriuretic peptide) levels were within normal limits. The patient was treated with nitroglycerin sublingually, beta blockers, ACE inhibitors and aspirin, with resolutions of symptoms. ECG taken several hours later showed a reduction of ischemic changes (Figure 3). Coronary angiography revealed multiple stenoses of anterior interventricular branch of the left coronary artery. Considering his cardiac status, further chemotherapy was discontinued.

\section{Discussion}

Cardiotoxicity occurs during therapy with several cytotoxic drugs and may be the dose limiting factor in cancer treatment and hence tumor response. Furthermore, cardiotoxicity can also be responsible for long term side effects and may cause severe morbidity in surviving cancer patients [2]. Cardiotoxicity includes a wide range of cardiac effects from small changes in blood pressure and arrhythmias to cardiomyopathy [2].

The underlying mechanisms of coronary artery diseases in cancer patients who are treated with anticancer agents may include:

1. Coexistent coronary atherosclerosis

2. Coronary compression or embolization by the tumor

3. Tumor-associated hypercoagulopathy

4. Vasculitis

5. Non-bacterial thrombotic endocarditis

6. Complications directly related to antineoplastic therapy [3-5]

Cisplatin is a known chemotherapy agent related to thrombosis. The proposed mechanisms are direct endovascular damage; decreased activity of anticoagulant protein C; elevated plasma vWf level, activation of an arachidonic pathway in platelets and hypomagnesaemia $[5,6]$. In retrospective study 87 long term survivors of metastatic testicular cancer treated with cisplatin major cardiac events were found in five (6\%) of the 87 patients [7]. In a study of 21 patients with testicular cancer treated with cisplatin, vinblastine and bleomicin, Stefenelli et al. found that $38 \%$ developed angina pectoris during chemotherapy [8]. In another of study, of 78 patients with lung cancer treated with cisplatin and etoposide, 3 patients developed myocardial infarction during chemotherapy [9]. Sawant et al. presented cases of 2 young

*Corresponding author: Daliborka Bursac, Faculty of Medicine Novi Sad, Institute for Pulmonary Diseases of Vojvodina, Sremska Kamenica, Serbia, Tel: +381 21 4805100; E-mail: dadabursac@gmail.com

Received: February 19, 2018; Accepted: March 22, 2018; Published: March 26, 2018

Citation: Bursac D (2018) Myocardial Ischemia during Combined Chemotherapy with Etoposide and Cisplatin for Non-Small Cell Lung Cancer. Oncol Cancer Case Rep 4: 141

Copyright: () 2018 Bursac D. This is an open-access article distributed under the terms of the Creative Commons Attribution License, which permits unrestricted use, distribution, and reproduction in any medium, provided the original author and source are credited. 
Citation: Bursac D (2018) Myocardial Ischemia during Combined Chemotherapy with Etoposide and Cisplatin for Non-Small Cell Lung Cancer. Oncol Cancer Case Rep 4: 141

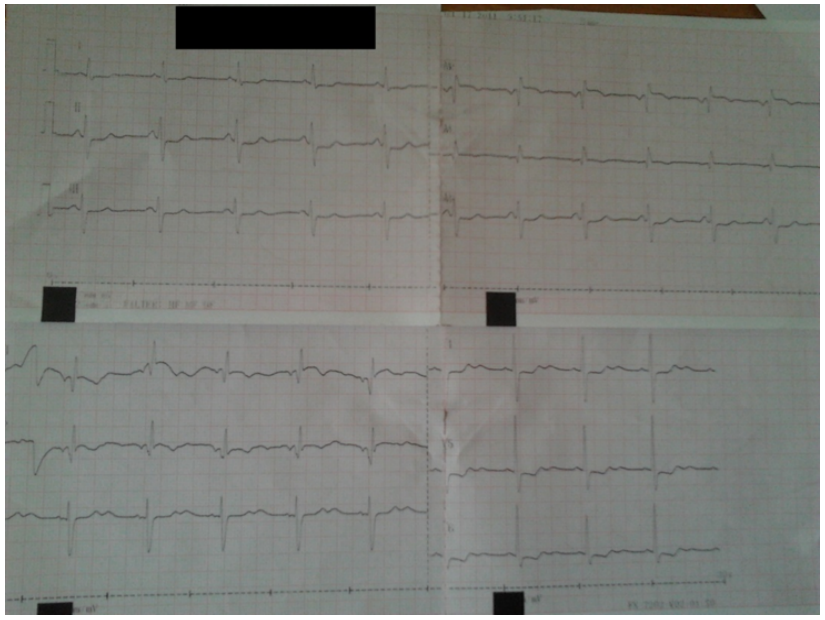

Figure 1: Electrocardiogram (ECG) before application of chemotherapy.

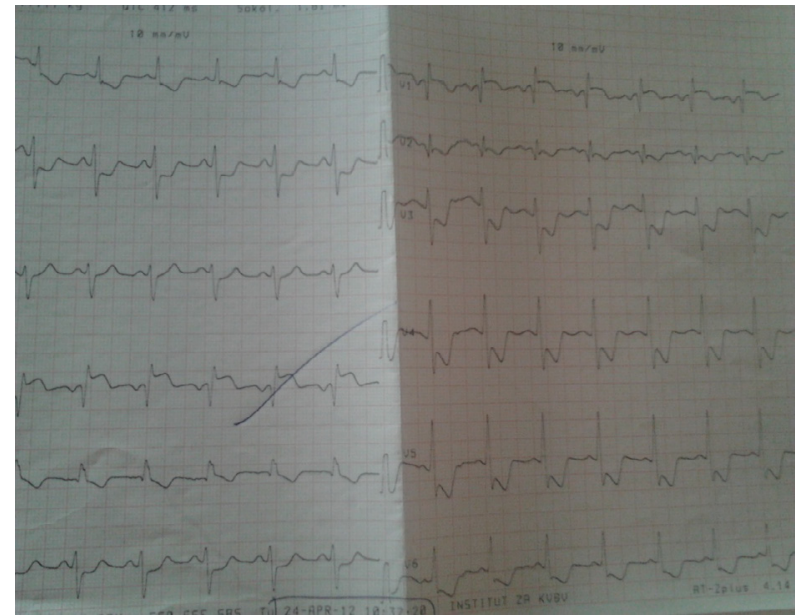

Figure 2: Electrocardiogram (ECG) at the time of chest pain.

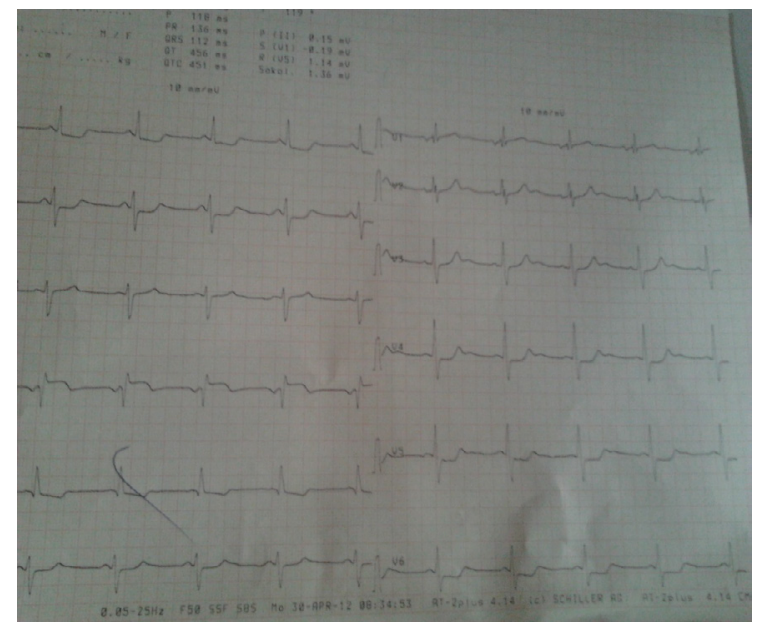

Figure 3: Electrocardiogram (ECG) taken 6 days after the above episode.

patients with acute myocardial infarction during chemotherapy with bleomycin, etoposide and cisplatin [10].

There is limited evidence to indicate that etoposide may be cardiovascular toxic. Sharwzer et al. suggested that etoposide had no such effect. The patient in their report continued treatment with etoposide for 14 months following a myocardial infarction which occurred during the treatment protocol containing bleomycin and etoposide. They proposed that the cardiovascular effects were caused by the combinations of the two agents rather than any individual effect [11]. However, Schecter et al. [10] reported a case of myocardial infarction in a 27 -year-old female receiving etoposide treatment as a single agent for persistent Hodgkin's disease [12].

In our patient endoluminal radiotherapy may have contributed to the myocardial ischemia, as it is known to cause endothelial injury and an increase in the inflammatory markers [13]. The exact mechanism for radiation-induced CAD is not understood. One possible mechanism is that radiation induces endothelial injury. Ionizing energy accelerates the deposition of cholesterol in the arterial wall and produces intimal and adventitial proliferation [13].

Our patient had important known risk factors for the occurrence myocardial ischemia. He was ex-smoker, with known history of hypertension and Coronary artery disease. The use of cardiotoxic chemotherapy agents in patients with established cardiovascular risk factors is challenging. Cardiotoxic chemotherapy can be used in special situations after considering the risk and benefit. Patients treated with chemotherapeutic agents, which are associated with vascular toxicity, should be monitored for cardiac ischemia, and these agents should be at least temporarily discontinued if a patient presents with acute coronary events $[13,14]$.

\section{Conclusion}

Patients with cancer in particular those with known cardiac risk factors are at risk for development of cardiotoxicity and need careful assessment of risk and benefit before initiation of chemotherapy agents which are known to have cardiac side effects.

\section{References}

1. Fernandes DD, Louzada ML, Souza CA Matzinger F (2011) Acute aortic thrombosis in patients receiving cisplatin-based chemotherapy. CurrentOncology 18: e97-e100.

2. Schimmel K, Richel D, Van-Den BRB, Guchelaar HJ (2004) Cardiotoxicity of cytotoxic drugs. Cancer Treatment Reviews 30: 181-191.

3. Pérez-Callejo D, Torrente M, Brenes MA, Núñez B, Provencio M (2017) Lung cancer as a cardiotoxic state: A review. Med Oncol 34: 159

4. Biasillo G, Cipolla CM, Cardinale D (2017) Cardio-oncology: Gaps in knowledge goals, advances, and educational efforts. Curr Oncol Rep 19: 55.

5. Fukuda M, Oka M, Itoh N, Sakamoto T, Mori H, et al. (1999) Vasospastic angina likely related to cisplatin-containing chemotherapy and thoracic irradiation for lung cancer. Internal Medicine 38: 436-438

6. Herradón E, González C, Uranga JA, Abalo R, Martín MI, et al. (2017) Characterization of cardiovascular alterations induced by different chronic cisplatin treatments. Frontiers Pharmacol 8: 196

7. Meinardi MT, Gietema JA, Van-der GWT, Van-Veldhuisen DJ, Runne MA, et al (2000) Cardiovascular morbidity in long-term survivors of metastatic testicular cancer. J Clin Oncol 18: 1725-1732.

8. Stefenelli T, Kuzmits R, Ulrich W, Glogar D (1988) Acute vascular toxicity after combination chemotherapy with cisplatin, vinblastine, and bleomycin for testicular cancer. Eur Heart J 9: 552-556.

9. Tsutsumi T, Ozawa Y, Kawakami A, Fujii H, Asamoto H (1990) Acute myocardia infarction induced by lung cancer chemotherapy with cisplatin and etoposide. Gan To Kagaku Ryoho 17: 413-417.

10. Sawant J, Prakruthi AD, Daddi J, Ghosh A, Joshi A, et al. (2015) Cisplatininduced cardiotoxicity- two case reports. Onco Review 5: 145-150.

11. Schwarzer S, Eber B, Greinix H, Lind P (1991) Non-Q wave myocardial 
Citation: Bursac D (2018) Myocardial Ischemia during Combined Chemotherapy with Etoposide and Cisplatin for Non-Small Cell Lung Cancer. Oncol Cancer Case Rep 4: 141

Page 3 of 3

infarction associated with bleomycin and etoposide chemotherapy. Eur Heart J 12: 748-750

12. Schecter JP, Jones SE, Jackson RA (1975) Myocardial infarction in a 27-yearold woman: possible complication of treatment with VP-16-213 (NSC-141540) mediastinal irradiation, or both (Letter). Cancer Chemther Rep 59: 887-888.
13. Yusuf SW, Razeghi P, Yeh ET (2008) The diagnosis and management of cardiovascular disease in cancer patients. Curr Probl Cardiol 33: 163-196.

14. Curigliano G, Cardinale D, Suter T, Plataniotis G, De Azambuja E, et al. (2012) Cardiovascular toxicity induced by chemotherapy, targeted agent and radiotherapy: ESMO Clinical Practice Guidelines. Ann Oncol 23: 155-166. 